\title{
Six months of aerobic exercise does not improve microvascular function in type $\mathbf{2}$ diabetes mellitus
}

\author{
A. R. Middlebrooke $\cdot$ L. M. Elston • K. M. MacLeod • \\ D. M. Mawson • C. I. Ball • A. C. Shore • J. E. Tooke
}

Received: 2 February 2006 /Accepted: 22 May 2006 / Published online: 30 August 2006

(C) Springer-Verlag 2006

\begin{abstract}
Aims/hypothesis Adults with type 2 diabetes mellitus have impaired microvascular function. It has been hypothesised that microvascular function may be restored through regular exercise. The aim of this study was to investigate whether 6 months of regular aerobic exercise would improve microvascular function in adults with type 2 diabetes.

Materials and methods Fifty-nine patients with type 2

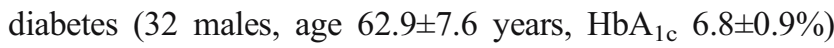
were randomised to either a 6-month aerobic exercise programme (30 $\mathrm{min}$, three times a week, $70-80 \%$ of maximal heart rate) or a 'standard care' control group. Before and after the intervention period, microvascular function was assessed as the maximum skin hyperaemia to local heating and endothelial and non-endothelial responsiveness following the iontophoretic application of acetylcholine and sodium nitroprusside. Maximal oxygen uptake, as an index of aerobic fitness, was assessed using a maximal exercise test.

Results No significant improvement was seen in the exercise group compared with the control group for any of the
\end{abstract}

L. M. Elston · K. M. MacLeod • D. M. Mawson • C. I. Ball •

A. C. Shore · J. E. Tooke

Diabetes and Vascular Medicine, Institute of Biomedical

and Clinical Science, Peninsula Medical School,

Exeter, UK

A. R. Middlebrooke

Children's Health and Exercise Research Centre,

School of Sport and Health Sciences, University of Exeter,

Exeter, UK

A. R. Middlebrooke ( $\square)$

School of Sport and Health Sciences, University of Exeter,

St Luke's Campus,

Exeter EX1 2LU, UK

e-mail: a.r.middlebrooke@exeter.ac.uk variables measured: maximal oxygen uptake (control pre: $1.73 \pm 0.53$ [means $\pm \mathrm{SD}$ ] vs post: $1.67 \pm 0.40$; exercise pre: $1.75 \pm 0.56$ vs post: $1.87 \pm 0.62 \mathrm{l} / \mathrm{min}, p=0.10)$; insulin sensitivity (insulin tolerance test) (control pre: $-0.17 \pm 0.06$ vs post: $-0.17 \pm 0.06$; exercise pre: $-0.16 \pm 0.1$ vs post: $-0.17 \pm$ $0.07 \mathrm{mmol} \mathrm{l}^{-1} \mathrm{~min}^{-1}, p=0.97$ ); maximal hyperaemia (control pre: $1.49 \pm 0.43$ vs post: $1.52 \pm 0.57$; exercise pre: $1.42 \pm 0.36$ vs post: $1.47 \pm 0.33 \mathrm{~V}, p=0.85$ ); peak response to acetylcholine (control pre: $1.37 \pm 0.47$ vs post: $1.28 \pm 0.37$; exercise pre: $1.27 \pm 0.44$ vs post: $1.44 \pm 0.23 \mathrm{~V}, p=0.19$ ) or to sodium nitroprusside (control pre: $1.09 \pm 0.50$ vs post: $1.10 \pm 0.39$; exercise pre: $1.12 \pm 0.28$ vs post: $1.13 \pm 0.40 \mathrm{~V}, p=0.98$ ).

Conclusions/interpretation In this group of type 2 diabetic patients with good glycaemic control a 6-month aerobic exercise programme did not improve microvascular function or aerobic fitness.

Keywords Aerobic $\cdot$ Diabetes $\cdot$ Exercise $\cdot$ Microvascular
Abbreviations
ACh acetylcholine
ITT insulin tolerance test
SNP sodium nitroprusside
TAC total antioxidant capacity
VST vibratory sensory threshold

\section{Introduction}

Patients with type 2 diabetes mellitus have an increased risk of cardiovascular disease and microvascular dysfunction even in the absence of traditional microvascular complications of the disease [1]. Increasing evidence suggests that microvascular function may be linked to the development of coronary heart disease in patients with type 2 diabetes 
[2] through the phenomenon of insulin resistance [3], which is associated with atherosclerosis [4]. Microvascular dysfunction may reflect underlying abnormalities in the endothelium, a key disturbance in the early development of atherosclerosis [5] and an intrinsic feature of the insulinresistance syndrome [6].

Increasing evidence suggests that regular exercise can improve macrovascular endothelial function in a number of populations in which endothelial dysfunction is common. These include individuals with chronic heart failure [7, 8] coronary artery occlusion [9], hypertension [10, 11], ageing [12], impaired glucose tolerance [13], type 1 diabetes [14] and type 2 diabetes [15], thereby supporting a role for regular exercise as a useful therapy for the reversal of endothelial dysfunction and the subsequent reduction in cardiovascular risk in these populations.

However, despite the accumulating evidence supporting the reversal of endothelial dysfunction in the macrocirculation, there is limited evidence in adults to suggest that regular aerobic exercise can augment performance of the microcirculation [16]. Therefore, the aim of the present study was to investigate whether 6 months of regular aerobic exercise would improve microvascular function in adults with type 2 diabetes.

\section{Subjects, materials and methods}

\section{Subjects}

Fifty-nine adults with type 2 diabetes $(27$ females and 32 males) aged 40 to 75 years were recruited from GP clinics, hospital outpatient clinics and from media advertisements for the study. All subjects provided their written, informed consent to the study, which had previously been approved by the Exeter and North Devon Local Medical Research Ethics Committee. The study was conducted in accordance with the principles of the Declaration of Helsinki as revised in 2000. The inclusion criteria were as follows: type 2 diabetes diagnosed at 33 years or older with no ketones at time of diagnosis, treated with diet alone or oral hypoglycaemic agents in the first instance and stable glycaemic control (most recent $\mathrm{HbA}_{1 \mathrm{c}}$ between 6 and 10\%). Subjects were excluded from the study if they were unable to exercise independently, give informed consent, had a clinical diagnosis of Raynaud's phenomenon or systemic vasculitis, had suffered a recent (within 6 months) myocardial infarction or stroke, had uncontrolled hypertension $(>160 / 90 \mathrm{mmHg})$, unstable angina, a pacemaker or an abnormal ECG. As expected in a cohort of adults with type 2 diabetes, the subjects were taking a number of antihypertensive, anticoagulant and lipid-lowering therapies (Table 1). However, subjects were excluded if they had
Table 1 Baseline clinical characteristics

\begin{tabular}{lll}
\hline & $\begin{array}{l}\text { Exercise } \\
\text { group } \\
(n=22)\end{array}$ & $\begin{array}{l}\text { Control } \\
\text { group } \\
(n=30)\end{array}$ \\
\hline $\begin{array}{l}\text { Age in years (means } \pm \text { SD) } \\
\begin{array}{l}\text { Duration of diabetes in years } \\
\text { (means } \pm \text { SD) }\end{array}\end{array}$ & $\begin{array}{l}61.8 \pm 7.7 \\
\text { Smoking status (present/past/never) }\end{array}$ & $\begin{array}{l}64.6 \pm 6.8 \\
4.9 \pm 4.4\end{array}$ \\
$\begin{array}{l}\text { Mode of glycaemic control } \\
\text { (diet/tablet/insulin) }\end{array}$ & $13 / 8 / 1$ & $1 / 13 / 16$ \\
Antihypertensive therapy & $13(59 \%)$ & $15(50 \%)$ \\
Statin therapy & $5(23 \%)$ & $10(33 \%)$ \\
Aspirin therapy & $9(41 \%)$ & $12(40 \%)$ \\
Vitamins & $4(18 \%)$ & $4(13 \%)$ \\
Hormone replacement therapy & $3(14 \%)$ & $3(10 \%)$ \\
Retinopathy & $4 / 0$ & $4 / 0$ \\
(background/proliferative) & $7(32 \%)$ & $11(37 \%)$ \\
Sensory neuropathy $(\mathrm{VST}>25 \mathrm{~V})$ & $2(9 \%)$ & $1(3 \%)$ \\
Autonomic neuropathy $(\mathrm{score}>10)$ & $3(14 \%)$ & $4(13 \%)$ \\
Microalbuminuria $(>20 \mu \mathrm{m} / \mathrm{min})$ &
\end{tabular}

Figures represent actual number (percentage of group) unless otherwise indicated

been taking medication known to influence vascular function directly for less than 6 months or were taking an irregular dose of such medication. Subjects underwent a clinical examination prior to their inclusion in the study.

Exercise programme

Following recruitment and baseline testing, the subjects were randomly assigned to either an active exercise group or a 'standard care' control group using random number generation. The active exercise group followed a 6-month programme of regular exercise consisting of three sessions of aerobic exercise per week of 30 min duration at an intensity of $70-80 \%$ of their individualised maximum heart rate defined during an exercise test to voluntary exhaustion. A 10- to 15-min warm-up and cool-down period was included before and after the exercise session, which included light aerobic exercise and appropriate stretching. Two out of the three sessions were supervised group exercise sessions and one session was an independent, home-based exercise session. The subjects were fitted with polar heart rate monitors (Polar Vantage NV; Polar Electro Oy, Kempele, Finland) during all exercise sessions to ensure the sessions were being conducted at the correct intensity and duration. In total, the exercise group were expected to complete 78 sessions over the 6-month period. Acceptable attendance to be included in the data analysis was set at $80 \%$ (62 sessions). Testing was performed at least $24 \mathrm{~h}$ after the last exercise session to minimise any acute effects. The control group were seen by the research 
team only on their test occasions and received standard care from their GP/outpatient department.

Anthropometric measurements

Skinfold measures were taken prior to the exercise test, at the tricep, bicep, subscapular and suprailiac sites as an indirect measure of body composition in accordance with previously used methods [17]. Three values were taken from each site and the median value was taken as the representative skinfold measure. The median of each site was then summed to produce a sum of skinfold thicknesses. All skinfold thicknesses were measured using skinfold callipers (Holtain, Crymych, Dyfed, UK). Stature was measured using a stadiometer (Seca, Birmingham, UK) with the subject bare-foot. Body weight was measured with the subject wearing exercise attire excluding footwear using electronic weighing scales (Seca). Waist circumference was measured using an anthropometric tape (Holtain).

Neurological assessments

Vibratory sensory threshold (VST) at the apex of each big toe was obtained using a biothesiometer (Bio-Medical Instrument Co., OH, USA). The VST is the frequency at which the subject first perceives the vibratory stimulus as the frequency of vibration is gradually increased from zero. Three values were obtained at each toe and the mean calculated. A mean of more than $25 \mathrm{~V}$ on either foot was considered indicative of significant neuropathy.

Five tests of autonomic function were performed: blood pressure response to standing; blood pressure response to sustained handgrip; heart rate response to standing; heart rate response to Valsalva; and heart rate response to deep breathing. An individual was scored for each test (normal $=1$, borderline $=2$, abnormal $=3$ ) enabling a total score for autonomic function to be allocated (minimum score possible $=5$, maximum score $=15$ ). The tests were performed to standard methodology as previously described [18]. A score of more than 10 was considered indicative of significant neuropathy.

\section{Assessment of microvascular function}

The subjects were asked to refrain from smoking and all medication on the day of the study and fast from 22:00 hours the previous day. Subjects were also asked to refrain from vigorous exercise in the preceding $24 \mathrm{~h}$. A fingertip capillary blood sample was taken on arrival at the research centre and the visit was postponed if the blood glucose was $<3.5$ or $>17 \mathrm{mmol} / 1$. All studies were conducted in a temperature-controlled environment $(22 \pm$ $0.5^{\circ} \mathrm{C}$ ), with the subjects lying in a supine position. Blood pressure was taken four times at 1-min intervals at the site of the left brachial artery using a semi-automatic blood pressure recorder (Dinamap Pro; GE Medical Systems, Milwaukee, WI, USA). The mean of the final three inflations were taken as the representative blood pressure. Skin temperature was measured continuously throughout the test using a thermocouple (Fluke 52; John Fluke MFG, WA, USA) attached to the flexor aspect of the right forearm.

Iontophoresis of acetylcholine (ACh) and sodium nitroprusside (SNP)

Iontophoresis is a non-invasive technique used for the transdermal delivery of charged substances. The delivery of a known substance into the skin is achieved by applying a small electrical charge with the opposite polarity to the substance; in this case the vasodilators ACh and SNP were applied. Laser Doppler perfusion imaging then non-invasively measures the increase in erythrocyte flux due to the direct application of vasodilators.

Following a 30-min acclimatisation period the skin erythrocyte flux was measured using laser Doppler perfusion imaging after the iontophoretic application of an endothelial-dependent (ACh) and -independent (SNP) vasodilator using a battery-powered iontophoresis controller (DRT4; Moor Instruments, Axminster, UK). A solution of $1 \% \mathrm{ACh}(20 \mathrm{mg} \mathrm{ACh}$ chloride and $56 \mathrm{mg}$ mannitol; Miochol-E; Novartis Pharmaceuticals UK, Camberley, UK) and an ACh vehicle solution (3\% mannitol; Royal Devon and Exeter Healthcare NHS Trust, Exeter, UK) was iontophoresed using an anodal (+ve) charge $(5 \times 0.1 \mathrm{~mA}$ for $20 \mathrm{~s}$ ) on three sites and one site, respectively. Forearm skin erythrocyte flux was measured prior to iontophoresis (baseline), during the iontophoresis and every $40 \mathrm{~s}$ following the completion of each charge. A solution of $0.25 \%$ SNP (F. H. Faulding, VC, Australia) and SNP vehicle (deionised water) was iontophoresed $(0.2 \mathrm{~mA}$ for $60 \mathrm{~s})$ using a cathodal charge (-ve) each to at least one site which had been anaesthetised with the topical application of a local anaesthetic cream (5\% EMLA; AstraZeneca, Luton, UK). Forearm skin erythrocyte flux was measured prior to iontophoresis (baseline) and after each 60 -s period for $6 \mathrm{~min}$. A $635-\mathrm{nm}$ wavelength solidstate laser Doppler perfusion imager (LDPI) (Lisca Development, Linköping, Sweden) was used to measure forearm skin erythrocyte flux at the site at which $\mathrm{ACh}$ and SNP were directly applied. Measurements from the LDPI were analysed using the Win 2.0.9. software (Lisca Development). The data were expressed as the mean forearm skin erythrocyte flux over an area of $0.78 \mathrm{~cm}^{2}$. A subject's individual response was calculated as the mean response of three drug sites. An individual's peak response 
was determined from the mean of the peak responses obtained on the separate iontophoresis experiments. Biological zeros were measured following arterial occlusion at both an inflamed (vasodilated) and a non-inflamed site. This provides a measurement of erythrocyte flux in the absence of blood flow. Arterial occlusion was provided by the inflation of a blood pressure cuff positioned on the upper right arm to a suprasystolic pressure $(220 \mathrm{mmHg})$. The responses to $\mathrm{ACh}$ and $\mathrm{SNP}$ are expressed as peak response and AUC. The intra-individual $\mathrm{CV}$ for the measurement of the ACh response was $12 \%$ and for the SNP response was $18.7 \%$, determined from five subjects on five separate occasions.

\section{Maximum hyperaemic response}

An area of the dorsal aspect of the right foot, clear of visible veins or skin lesions, was heated to a temperature of $42^{\circ} \mathrm{C}$ for 30 min with a small brass heater of $1 \mathrm{~cm}$ in diameter (Moor Instruments) and the maximum hyperaemic response was measured using laser Doppler fluximetry (Periflux Pf2; Perimed, Stockholm, Sweden). The erythrocyte flux was measured for a period of $30 \mathrm{~s}$ at each of eight non-centric sites within the heated area and the erythrocyte flux was calculated as the mean of the eight sites. This measure is the maximum achievable microvascular blood flow. The mean intra-individual CV for the measurement of maximum hyperaemia was $6.6 \%$ determined from two subjects on five separate occasions.

\section{Blood samples}

Fasting samples of $\mathrm{HbA}_{1 \mathrm{c}}$, glucose, insulin, total cholesterol, HDL-cholesterol, LDL-cholesterol, triglycerides, IL-6 and total antioxidant capacity (TAC) were measured. $\mathrm{HbA}_{1 \mathrm{c}}$ was measured using HPLC (Tosoh G7 HPLC System; Tosoh Bioscience, Redditch, UK). Plasma glucose, total cholester$\mathrm{ol}$, triglycerides and HDL-cholesterol were measured using a Roche modular analyser (Roche Diagnostics, Lewes, UK), LDL-cholesterol was calculated using the Friedewald formula [19] and insulin was measured using an immunoenzymometric assay (Appligene Oncor/Lifescreen, Uxbridge, UK) calibrated against IRP66/304 with no detectable crossreactivity with intact proinsulin or 32,33 split proinsulin. IL-6 was measured using a highly sensitive human IL-6 ELISA (R\&D Systems, Abingdon, UK). TACs of duplicate $5-\mu$ l samples of plasma were determined in the ABEL antioxidant assay with pholasin peroxynitrate (Knight Scientific, Plymouth, UK). The CV for $\mathrm{HbA}_{1 \mathrm{c}}$ was $2.0 \%$, for glucose $1.8 \%$, for insulin $<10 \%$ over the range $95-1,038 \mathrm{pmol} / 1$, for total cholesterol $2.8 \%$, for triglycerides $4.7 \%$, for HDL-cholesterol $2.6 \%$, for IL-6 7.2\% and for TAC $1.8 \%$.
Insulin Tolerance Test (ITT)

Insulin sensitivity was assessed using a 15-min continuous ITT. Following an overnight fast and abstention from medication, the subject was laid partially supine. A bolus of $0.1 \mathrm{U} / \mathrm{kg}$ of insulin (Human Actrapid; Novo Nordisk Pharmaceuticals, Crawley, UK) was infused into a vein at the site of the antecubital fossa. Blood samples for the determination of blood glucose were taken each minute for $15 \mathrm{~min}$. The glucose samples were measured in duplicate (YSI2300 Stat Plus; Yellowsprings Instruments, Yellowsprings, OH, USA). The slope of the blood glucose curve was used in subsequent analysis.

Determination of maximal oxygen uptake

All subjects performed a continuous incremental exercise test to voluntary exhaustion on a cycle ergometer (Lode Excalibur; Lode, Groningen, the Netherlands). The test consisted of a 4-min warm-up with a workload of $30 \mathrm{~W}$ followed by a continuous incremental exercise test $(25 \mathrm{~W} /$ min) until voluntary exhaustion was achieved. Immediately prior to and after the exercise test, fingertip blood samples (approximately $25 \mu \mathrm{l}$ ) were taken into $300-\mu$ l fluorideheparin microvettes (Sarstedt, Nümbracht, Germany) and analysed immediately for the determination of blood glucose and lactate concentrations (Yellowsprings Instruments). The subject was judged to have attained maximal oxygen uptake when two of the following criteria were met: (1) heart rate within 10 beats/min of age-predicted maximum heart rate; (2) respiratory exchange ratio greater than 1.0 ; and (3) a plateau of oxygen uptake values.

Metabolic variables were measured continuously throughout the test using an on-line gas analysis system (Morgan Medical EX-670; Morgan Medical, Guildford, UK). Prior to each test, gas and volume calibrations were performed. The gas calibration consisted of a four-point calibration: 5\% carbon dioxide, $15 \%$ oxygen, $75 \%$ nitrogen and $5 \%$ argon. The volume calibration consisted of a known volume of air (31) being expired through the turbine. Expired gases were sampled on a breath-by-breath basis and recorded as 15-s averages for data analysis. Heart rate was measured continuously throughout the test using a 12-lead ECG system interfaced with the on-line gas analysis system (Morgan Medical).

\section{Statistical analysis}

All data were analysed using SPSS for Windows (Version 11.5; SPSS, Chicago, IL, USA). Normality of data distribution was assessed using a Kolmogorov-Smirnov analysis. Two-way ANOVA with repeated measures was used to examine whether the change in a parameter over time differed between those subjects who undertook exercise and those 
who did not. An unpaired $t$-test was used to examine the differences in baseline characteristics between the two groups. Data are presented as means $\pm \mathrm{SD}$ where normality of distribution is confirmed. A significance level of $p<0.05$ was set for all analyses. The sample size calculations $(n=30)$ were originally calculated to provide $90 \%$ power at the $5 \%$ significance level $(p=0.05)$ of detecting a $0.6 \mathrm{SD}$ difference between groups (two-sample test) and to be able to detect $0.18 \mathrm{~V}$ difference between the change from baseline scores in the exercising compared with the non-exercising cohort (ANOVA with repeated measures).

\section{Results}

Compliance with the exercise programme

In total, 59 subjects were recruited to the study. Seven subjects from the exercise group and none from the control group dropped out of the study. Three dropped out for health reasons, two were due to time constraints and two gave no reason for dropping out. Therefore, 52 subjects completed the study. Twenty-one of the 22 exercisers completed the necessary 78 exercise sessions (100\%) over 6 months at the appropriate intensity and duration and no significant adverse events occurred. The remaining one subject completed 68 exercise sessions (87\%).

Comparison of exercise and control subjects at baseline

The groups were well matched in terms of therapeutic management and presence of diabetic complications (Table 1). There was no significant difference between the exercise group and the control group for any baseline variable (unpaired $t$-test, $p>0.05$ ) (Table 2).

Effect of 6 months of aerobic exercise on anthropometry and maximal oxygen uptake

There were no significant changes in sum of skinfolds, body mass, BMI, waist circumference or maximal oxygen uptake in the exercise group following 6 months of regular aerobic exercise compared with the control group (Table 2).

Effect of 6 months of aerobic exercise on microvascular function

There were no significant correlations between maximal oxygen uptake and microvascular parameters before or after the 6-month intervention in either the exercise or control group. There were no significant changes in maximum hyperaemia, the peak response to $\mathrm{ACh}$, the peak response to SNP or the respective AUCs following the 6-month exercise intervention compared with the control group (Figs. 1, 2). The drug vehicles did not cause significant vasodilation and analysis with or without subtraction of the vehicle response did not alter the findings.

Effect of 6 months of aerobic exercise on blood pressure, haematology and insulin sensitivity

There were no significant changes in systolic or diastolic blood pressure, $\mathrm{HbA}_{1 \mathrm{c}}$, glucose, insulin, total cholesterol, HDL-cholesterol, LDL-cholesterol, triglycerides, IL-6, TAC, beta-cell function or insulin sensitivity measured by ITT (Table 2).

\section{Discussion}

The principal finding of this study is that in this cohort of adult type 2 diabetic patients with good glycaemic control, 6 months of regular aerobic exercise training (three times per week at $70-80 \%$ of maximal heart rate) did not significantly improve microvascular endothelial, smooth muscle cell or maximum hyperaemic function, aerobic fitness or cardiovascular risk factors in patients randomised to receive intensive personalised and supervised exercise training compared with those randomised to receive 'standard care'.

In agreement with our findings, previous work has demonstrated that a 6-month lifestyle intervention programme of dietary restriction and regular exercise in obese subjects with insulin-resistance syndrome failed to improve the reactivity of the cutaneous microcirculation [20]. Interestingly, these authors provided evidence to suggest that there may be differential effects of exercise on the macro- and microcirculation as flow-mediated dilation of the brachial artery was significantly enhanced following the lifestyle intervention.

An improvement in conduit and resistance vessel endothelial function following exercise training has been demonstrated in adults with conditions commonly associated with endothelial dysfunction, such as chronic heart failure [7, 8], coronary artery disease [21, 22], heart transplantation [23], hypertension [10, 11], impaired glucose tolerance [13], type 1 diabetes [14] and type 2 diabetes [15]. However, studies that have investigated the effect of exercise training on microvascular function are more limited and the findings unequivocal. Eight weeks of aerobic exercise training (5 days per week for 8 weeks at $50 \%$ maximal oxygen uptake) have been shown to stimulate an improvement in the responsiveness of the skin microcirculation in healthy adults [16], whereas the only previous study in type 2 diabetes showed that a similar period of aerobic training was without effect on the 
Table 2 Effect of the 6-month exercise intervention

\begin{tabular}{|c|c|c|c|c|c|}
\hline & $\begin{array}{l}\text { Exercise group } \\
\text { at baseline }\end{array}$ & $\begin{array}{l}\text { Exercise group } \\
\text { at } 6 \text { months }\end{array}$ & $\begin{array}{l}\text { Control group } \\
\text { at baseline }\end{array}$ & $\begin{array}{l}\text { Control group } \\
\text { at } 6 \text { months }\end{array}$ & $\begin{array}{l}p \text {-value } \\
\text { ANOVA }\end{array}$ \\
\hline Body mass (kg) & $90.7 \pm 13.5$ & $91.1 \pm 13.2$ & $87.5 \pm 17.5$ & $87.8 \pm 18.8$ & 0.90 \\
\hline BMI $\left(\mathrm{kg} / \mathrm{m}^{2}\right)$ & $31.8 \pm 4.5$ & $31.8 \pm 4.0$ & $29.9 \pm 5.4$ & $30.1 \pm 6.1$ & 0.50 \\
\hline Waist circumference $(\mathrm{cm})$ & $103.8 \pm 10.6$ & $103.5 \pm 11.2$ & $98.2 \pm 9.1$ & $99.2 \pm 9.0$ & 0.25 \\
\hline Total skinfolds (mm) & $74.5 \pm 17.6$ & $76.2 \pm 18.2$ & $65.1 \pm 19.7$ & $64.7 \pm 18.1$ & 0.46 \\
\hline Maximal oxygen uptake (1/min) & $1.75 \pm 0.56$ & $1.87 \pm 0.62$ & $1.73 \pm 0.53$ & $1.67 \pm 0.40$ & 0.10 \\
\hline Maximal oxygen uptake $\left(\mathrm{ml} \mathrm{kg}^{-1} \min ^{-1}\right)$ & $19.34 \pm 5.17$ & $20.43 \pm 5.67$ & $20.11 \pm 5.33$ & $19.25 \pm 4.08$ & 0.14 \\
\hline Maximum hyperaemia (V) & $1.42 \pm 0.36(22)$ & $1.47 \pm 0.33(22)$ & $1.49 \pm 0.43$ & $1.52 \pm 0.57$ & 0.85 \\
\hline Peak ACh response $(\mathrm{V})$ & $1.27 \pm 0.44(11)$ & $1.44 \pm 0.23(11)$ & $1.37 \pm 0.47(26)$ & $1.28 \pm 0.37(26)$ & 0.19 \\
\hline ACh AUC (V×time) & $304.38 \pm 133.06(11)$ & $313.02 \pm 71.38(11)$ & $321.44 \pm 131.28(26)$ & $300.13 \pm 124.75(26)$ & 0.57 \\
\hline Peak SNP response (V) & $1.12 \pm 0.28(9)$ & $1.13 \pm 0.40(9)$ & $1.09 \pm 0.50(24)$ & $1.10 \pm 0.39(24)$ & 0.98 \\
\hline SNP AUC $(\mathrm{V} \times$ time $)$ & $184.67 \pm 76.49(9)$ & $170.13 \pm 88.96(9)$ & $179.25 \pm 105.96(24)$ & $170.60 \pm 86.76(24)$ & 0.90 \\
\hline Systolic BP (mmHg) & $135 \pm 16$ & $133 \pm 18$ & $136 \pm 17$ & $135 \pm 18$ & 0.76 \\
\hline Diastolic BP (mmHg) & $75 \pm 11$ & $74 \pm 12$ & $74 \pm 7$ & $73 \pm 7$ & 0.98 \\
\hline $\mathrm{HbA}_{1 \mathrm{c}}(\%)$ & $6.8 \pm 0.9$ & $6.9 \pm 1.1$ & $7.2 \pm 1.1$ & $7.2 \pm 0.9$ & 0.38 \\
\hline Glucose (mmol/l) & $8.03 \pm 2.64$ & $8.18 \pm 2.09$ & $7.89 \pm 1.94$ & $8.48 \pm 2.60$ & 0.51 \\
\hline Serum insulin concentration (pmol/l) & $115.7 \pm 39.1$ & $130.2 \pm 53.2$ & $124.8 \pm 63.3$ & $122.7 \pm 87.4$ & 0.23 \\
\hline Total cholesterol $(\mathrm{mmol} / \mathrm{l})$ & $5.3 \pm 1.0$ & $5.2 \pm 1.0$ & $4.9 \pm 0.8$ & $4.9 \pm 0.9$ & 0.84 \\
\hline HDL-cholesterol (mmol/l) & $1.17 \pm 0.35$ & $1.21 \pm 0.36$ & $1.27 \pm 0.38$ & $1.30 \pm 0.39$ & 0.77 \\
\hline LDL-cholesterol (mmol/l) & $3.25 \pm 0.93$ & $3.16 \pm 0.96$ & $2.82 \pm 0.67$ & $2.80 \pm 0.87$ & 0.69 \\
\hline Triglycerides $(\mathrm{mmol} / \mathrm{l})$ & $1.88 \pm 0.85$ & $1.88 \pm 0.72$ & $1.92 \pm 1.16$ & $2.05 \pm 1.57$ & 0.57 \\
\hline IL-6 $(\mathrm{mmol} / \mathrm{l})$ & $1.19 \pm 0.69$ & $1.23 \pm 0.65$ & $1.66 \pm 1.69$ & $1.77 \pm 1.86$ & $0.73^{+}$ \\
\hline TAC (VEA equivalent units, $\mu \mathrm{mol} / \mathrm{l}$ ) & $386 \pm 50$ & $372 \pm 49$ & $369 \pm 66$ & $368 \pm 60$ & 0.26 \\
\hline $\begin{array}{l}\text { Insulin tolerance test slope } \\
\left(\mathrm{mmol}{ }^{-1} \mathrm{~min}^{-1}\right)\end{array}$ & $-0.16 \pm 0.10$ & $-0.17 \pm 0.07$ & $-0.17 \pm 0.06$ & $-0.17 \pm 0.06$ & 0.97 \\
\hline
\end{tabular}

Values are means $\pm \mathrm{SD} ; n=30$ for each group unless indicated otherwise as $(n)$

$V E A$ Vitamin E analogue

${ }^{*} p<0.05$

${ }^{+}$Performed on log-transformed data. There was no significant difference between the exercise and control group for any baselines variable (unpaired $t$-test, $p>0.05$ )

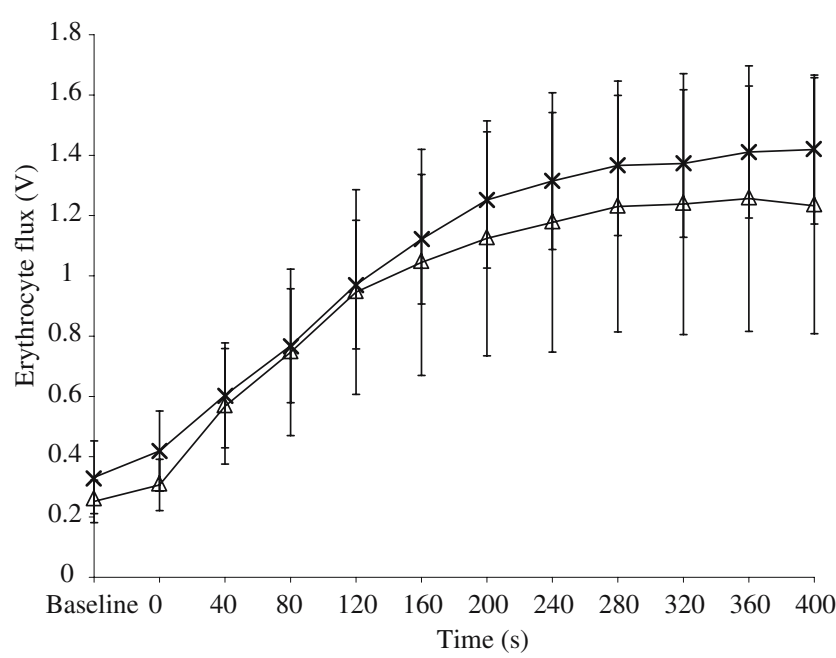

Fig. 1 Erythrocyte flux response to ACh in the exercise group at baseline (triangles) and 6 months (crosses). Error bars are SD

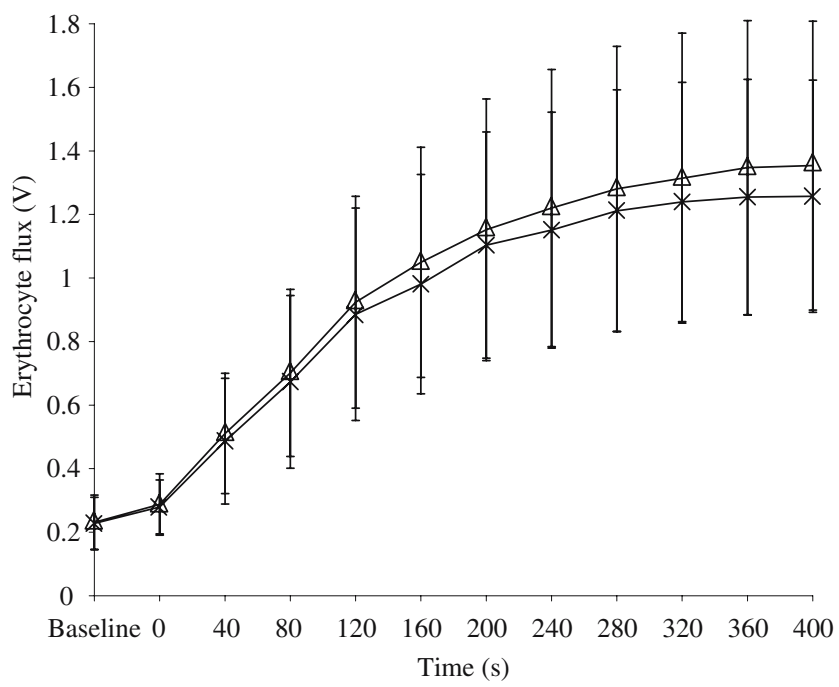

Fig. 2 Erythrocyte flux response to ACh in the control group at baseline (triangles) and 6 months (crosses). Error bars are SD 
maximum skin microvascular hyperaemia or interstitial nitric oxide levels [24]. The effects of prolonged exercise training on microvascular function had not been investigated prior to the current study in type 2 diabetes.

Studies that have demonstrated an improvement in conduit or resistance vessel endothelial function following exercise training have commonly demonstrated a corresponding increase in aerobic fitness, defined by maximal oxygen uptake [7, 13-16, 21, 23, 25], suggesting that an improvement in endothelial function improves the ability to supply and utilise oxygen during exercise (increase aerobic fitness) or that the improvement is driven by a common factor. In keeping with this concept that improving skeletal muscle perfusion improves aerobic fitness, it has been demonstrated that 18 weeks of exercise training improve capillary supply in healthy men and that this is correlated with a significant improvement in aerobic fitness [26]. The present authors also reported a direct relationship between the level of aerobic fitness and microvascular function in adults with an increased risk of developing type 2 diabetes [27], with a similar relationship described in heart transplant recipients [28]. However, correlation analyses revealed there was no significant association between aerobic fitness (maximal oxygen uptake) and microvascular function either before or after the exercise intervention in the present study, which suggests that in this type 2 diabetic cohort, aerobic fitness may be more markedly influenced by other factors determining oxygen delivery/utilisation, such as mitochondrial function. The lack of a significant improvement in aerobic fitness, cardiovascular risk factors and microvascular parameters is unlikely to represent a lack of exercise stimulus, as the exercise group demonstrated excellent adherence to the training programme. The programme was equivalent in intensity, frequency and duration to current guidelines on the appropriate intervention to improve glycaemic control, assist with weight maintenance and reduce cardiovascular risk in type 2 diabetes [29]. A recent meta-analysis concluded that regular aerobic exercise improves aerobic fitness in type 2 diabetes [30]. However, the limited number of included studies provided a wide range of improvements in aerobic fitness (2.9-40\%) with higher exercise intensities tending to produce the greatest improvements in aerobic fitness [31] and the smallest improvements in newly diagnosed patients [32]. The present study has demonstrated a non-significant $5.6 \%$ increase in aerobic fitness, which is within the range of improvements demonstrated in the meta-analysis. Since our patient cohort has a relatively short duration of disease the meta-analysis would predict only a small effect of exercise, as was observed. Furthermore many studies specifically recruit sedentary patients into an exercise study, i.e. patients in whom marked improvement are likely to be observed. This was not the case in the current study. It has recently been suggested that improvements in vascular function following exercise training may be independent of alterations in traditional cardiovascular risk factors [33]; the lack of significant improvements in cardiovascular risk factors is therefore unlikely to be the reason for a lack of improvement in microvascular function.

The lack of effect on microvascular function may reflect a response to the relatively high intensity (70-80\% maximum heart rate, $\sim 60-70 \%$ maximal oxygen uptake) of the exercise programme. It has recently been demonstrated that 12 weeks of exercise undertaken at low $(25 \%$ maximal oxygen uptake) and high (75\% maximal oxygen uptake) intensity had no effect on ACh-mediated endothelial function in young healthy men; only moderate-intensity exercise (50\% maximal oxygen uptake) improved AChmediated endothelial function. The authors suggested that the low-intensity exercise may fall below the threshold needed for improvement while the improvement in highintensity exercise may have been abolished by free radicals generated at high intensities [34]. Although the TAC remained unchanged following the intervention in the exercise group compared with the control group, this would not necessarily reflect the acute increase in oxidative stress associated with a single exercise bout [35].

Although the final numbers available in the microvascular parameters were reduced the study retained $90 \%$ power (5\% significance) to detect a $0.3 \mathrm{~V}$ difference for ACh between the change from baseline scores in the exercising compared with the non-exercising cohort (ANOVA with repeated measures) and a $0.20 \mathrm{~V}$ change for maximum hyperaemia. Since the mean difference between type 2 diabetes and normal controls is 0.50 and $0.44 \mathrm{~V}$, respectively $[36,37]$, this represents a clinically relevant reversal of the abnormalities described. In terms of SD improvement, these represent 0.8 and 0.74 SD, which are smaller than many changes previously described for exercise-induced changes of the macrocirculation, many of which are multiples of SDs [13, 38, 39]. A type 2 error is therefore unlikely to explain the lack of an effect of exercise on microvascular function.

The most likely explanation for our findings relate to our patient cohort. They represent the clinic population of patients with diabetes of moderately short duration who are receiving the best in contemporary control of their diabetes and risk factors. Many were taking antihypertensive and lipid-lowering therapies and were not sedentary. In this cohort, improvements in vascular function may have already occurred and thus an exercise intervention was without a major further role. The important message for the clinical care of patients with diabetes is that not all patients will benefit to the same degree from adherence to a rigorous exercise programme. Thus lack of alteration in risk factors does not necessarily indicate lack of compliance with the exercise programme. 
In conclusion, the present study has demonstrated that 6 months of regular aerobic exercise did not improve fitness or the performance of the microcirculation in adults with type 2 diabetes on contemporary treatment. In contrast, previous studies have reported exercise-induced improvements in both aerobic fitness and conduit and resistance vessel endothelial function, suggesting a commonality of function. One possible interpretation is that the micro- and macrocirculation respond differently to the exercise stimulus. Further investigation is required to explore this aspect and to determine whether different exercise regimes or different subgroups of diabetic or insulin-resistant subjects are more responsive to this strongly advocated lifestyle intervention.

Acknowledgements This study was funded by a grant from the National Lottery Charities Board. We would like to thank the Royal Devon and Exeter Hospital Foundation Trust for the use of their facilities, J. Knight for the TAC analysis and G. Batten for IL-6 analysis. A. R. Middlebrooke and L. M. Elston made an equal contribution to this paper.

\section{References}

1. Jaap AJ, Pym CA, Seamark C, Shore AC, Tooke JE (1995) Microvascular function in type 2 (non-insulin-dependent) diabetes: improved vasodilation after one year of good glycaemic control. Diabet Med 12:1086-1091

2. Wong TY, Rosamond W, Chang PP et al (2005) Retinopathy and risk of congestive heart failure. JAMA 293:63-69

3. de Jongh RT, Serne EH, Ijzerman RG, de Vries G, Stehouwer CD (2004) Impaired microvascular function in obesity: implications for obesity-associated microangiopathy, hypertension, and insulin resistance. Circulation 109:2529-2535

4. Watson KE, Peters Harmel AL, Matson G (2003) Atherosclerosis in type 2 diabetes mellitus: the role of insulin resistance. J Cardiovasc Pharmacol Ther 8:253-260

5. Ross R (1993) The pathogenesis of atherosclerosis: a perspective for the 1990s. Nature 362:801-809

6. Tooke JE, Hannemann MM (2000) Adverse endothelial function and the insulin resistance syndrome. J Intern Med 247:425-431

7. Hambrecht R, Fiehn E, Weigl C et al (1998) Regular physical exercise corrects endothelial dysfunction and improves exercise capacity in patients with chronic heart failure. Circulation 98: 2709-2715

8. Maiorana A, O’Driscoll G, Dembo L et al (2000) Effect of aerobic and resistance exercise training on vascular function in heart failure. Am J Physiol Heart Circ Physiol 279:H1999-H2005

9. Griffin KL, Laughlin MH, Parker JL (1999) Exercise training improves endothelium-mediated vasorelaxation after chronic coronary occlusion. J Appl Physiol 87:1948-1956

10. Ferguson DW (2000) Regular aerobic exercise augments endothelium-dependent vascular relaxation in normotensive and hypertensive subjects: role of endothelium-derived nitric oxide. Circulation 102:E119-E120

11. Higashi Y, Sasaki S, Kurisu S et al (1999) Regular aerobic exercise augments endothelium-dependent vascular relaxation in normotensive as well as hypertensive subjects: role of endothelium-derived nitric oxide. Circulation 100:1194-1202

12. DeSouza CA, Shapiro LF, Clevenger CM et al (2000) Regular aerobic exercise prevents and restores age-related declines in endothelium-dependent vasodilation in healthy men. Circulation 102:1351-1357

13. Xiang GD, Wang YL (2004) Regular aerobic exercise training improves endothelium-dependent arterial dilation in patients with impaired fasting glucose. Diabetes Care 27:801-802

14. Fuchsjager-Mayrl G, Pleiner J, Wiesinger GF et al (2002) Exercise training improves vascular endothelial function in patients with type 1 diabetes. Diabetes Care 25:1795-1801

15. Maiorana A, O'Driscoll G, Cheetham C et al (2001) The effect of combined aerobic and resistance exercise training on vascular function in type 2 diabetes. J Am Coll Cardiol 38:860-866

16. Wang JS (2005) Effects of exercise training and detraining on cutaneous microvascular function in man: the regulatory role of endothelium-dependent dilation in skin vasculature. Eur J Appl Physiol 93:429-434

17. Harrison GG, Buskirk ER, Lindsay Carter JE et al (1988) Skinfold thicknesses and measurement technique. In: Lohman TG, Roche AF, Martorell R (eds) Anthropometric standardization references manual. Human Kinetics, Champaign, pp 55-70

18. Vinik AI, Maser RE, Mitchell BD, Freeman R (2003) Diabetic autonomic neuropathy. Diabetes Care 26:1553-1579

19. Friedewald WT, Levy RI, Fredrickson DS (1972) Estimation of the concentration of low-density lipoprotein cholesterol in plasma, without use of the preparative ultracentrifuge. Clin Chem 18:499-502

20. Hamdy O, Ledbury S, Mullooly C et al (2003) Lifestyle modification improves endothelial function in obese subjects with the insulin resistance syndrome. Diabetes Care 26: $2119-2125$

21. Hambrecht R, Wolf A, Gielen S et al (2000) Effect of exercise on coronary endothelial function in patients with coronary artery disease. N Engl J Med 342:454-460

22. Edwards DG, Schofield RS, Lennon SL, Pierce GL, Nichols WW, Braith RW (2004) Effect of exercise training on endothelial function in men with coronary artery disease. Am J Cardiol 93:617-620

23. Schmidt A, Pleiner J, Bayerle-Eder M et al (2002) Regular physical exercise improves endothelial function in heart transplant recipients. Clin Transplant 16:137-143

24. Colberg SR, Parson HK, Nunnold T, Holton DR, Swain DP, Vinik AI (2005) Change in cutaneous perfusion following 10 weeks of aerobic training in type 2 diabetes. J Diabetes Complications 19:276-283

25. Gokce N, Vita JA, Bader DS et al (2002) Effect of exercise on upper and lower extremity endothelial function in patients with coronary artery disease. Am J Cardiol 90:124-127

26. Hepple RT, Mackinnon SL, Goodman JM, Thomas SG, Plyley MJ (1997) Resistance and aerobic training in older men: effects on $\mathrm{VO}_{2}$ peak and the capillary supply to skeletal muscle. J Appl Physiol 82:1305-1310

27. Middlebrooke AR, Armstrong N, Welsman JR, Shore AC, Clark P, Macleod KM (2005) Does aerobic fitness influence microvascular function in healthy adults at risk of developing type 2 diabetes? Diabet Med 22:483-489

28. Andreassen AK, Kvernebo K, Jorgensen B, Simonsen S, Kjekshus J, Gullestad L (1998) Exercise capacity in heart transplant recipients: relation to impaired endothelium-dependent vasodilation of the peripheral microcirculation. Am Heart $\mathrm{J}$ $136: 320-328$

29. Sigal RJ, Kenny GP, Wasserman DH, Castaneda-Sceppa C (2004) Physical activity/exercise and type 2 diabetes. Diabetes Care 27:2518-2539

30. Boule NG, Kenny GP, Haddad E, Wells GA, Sigal RJ (2003) Meta-analysis of the effect of structured exercise training on cardiorespiratory fitness in type 2 diabetes mellitus. Diabetologia 46:1071-1081 
31. Mourier A, Gautier JF, De Kerviler E et al (1997) Mobilization of visceral adipose tissue related to the improvement in insulin sensitivity in response to physical training in NIDDM. Effects of branched-chain amino acid supplements. Diabetes Care 20: 385-391

32. Vanninen E, Uusitupa M, Siitonen O, Laitinen J, Lansimies E (1992) Habitual physical activity, aerobic capacity and metabolic control in patients with newly-diagnosed type 2 (non-insulindependent) diabetes mellitus: effect of 1-year diet and exercise intervention. Diabetologia 35:340-346

33. Green DJ, Walsh JH, Maiorana A, Best MJ, Taylor RR, O'Driscoll JG (2003) Exercise-induced improvement in endothelial dysfunction is not mediated by changes in CV risk factors: pooled analysis of diverse patient populations. Am J Physiol Heart Circ Physiol 285:H2679-H2687

34. Goto C, Higashi Y, Kimura M et al (2003) Effect of different intensities of exercise on endothelium-dependent vasodilation in humans: role of endothelium-dependent nitric oxide and oxidative stress. Circulation 108:530-535
35. Elokda AS, Shields RK, Nielsen DH (2005) Effects of a maximal graded exercise test on glutathione as a marker of acute oxidative stress. J Cardiopulm Rehabil 25:215-219

36. Morris SJ, Shore AC, Tooke JE (1995) Responses of the skin microcirculation to acetylcholine and sodium nitroprusside in patients with NIDDM. Diabetologia 38:1337-1344

37. Sandeman DD, Pym CA, Green EM, Seamark C, Shore AC, Tooke JE (1991) Microvascular vasodilatation in feet of newly diagnosed non-insulin dependent diabetic patients. BMJ 302: $1122-1123$

38. Watts GF, O'Brien SF, Silvester W, Millar JA (1996) Impaired endothelium-dependent and independent dilatation of forearm resistance arteries in men with diet-treated non-insulin-dependent diabetes: role of dyslipidaemia. Clin Sci (Lond) 91:567-573

39. Green DJ, Walsh JH, Maiorana A, Burke V, Taylor RR, O'Driscoll JG (2004) Comparison of resistance and conduit vessel nitric oxide-mediated vascular function in vivo: effects of exercise training. J Appl Physiol 97:749-755 